\title{
Insulin sensitizing agent improves clinical pregnancy rate and insulin resistant parameters in polycystic ovarian syndrome patients with acanthosis nigricans: a randomized controlled study
}

\author{
Safwat A. Salman, MD, ${ }^{1}$ Dalia A. Attallah, MD, ${ }^{2}$ Mohammed K. Ali, MD, ${ }^{1}$ Heba A. \\ Hafez, MD, ${ }^{3}$ Tarek A. Farghaly, MD, ${ }^{1}$ Omar M. Shaaban, MD ${ }^{1}$
}

Keywords: Acanthosis nigricans, clomiphene citrate, metformin, polycystic ovary syndrome, insulin resistance, pregnancy

\begin{abstract}
Objective: To investigate the effect of adding metformin to clomiphene citrate (CC) in polycystic ovarian syndrome (PCOS) patients with acanthosis nigricans (AN) who were previously not responding to CC.

Material and Methods: A double blinded randomized controlled trial (NCT02562664) included 66 PCOS women with acanthosis nigricans who were CC resistant (at least 3 months). Day 3 follicle stimulating hormone (FSH) level, fasting insulin, fasting glucose and homeostatic model assessment were used to quantify insulin resistance. Participants were randomly assigned to either group I (CC with placebo tablets) or group II (CC with metformin) for three cycles. Insulin resistance parameters as well as clinical pregnancy rate had been evaluated in both groups. The statistical analysis was done using Chi- square and Fischer exact tests.
\end{abstract}

Results: The demographic data was comparable in both groups, however; there was higher cumulative pregnancy rate after three cycles of stimulation in group II (18/33) (54.5\%) in comparison with group I (7/33) (21.1\%) $(P=0.03)$. There was a significant improvement in the insulin resistance parameters after three months of combining clomiphene citrate with metformin as compared with CC alone.

Conclusion: Adding metformin to $\mathrm{CC}$ in clomiphene citrate resistant PCOS patients who have acanthosis nigricans improves the pregnancy rate and insulin resistant parameters.

${ }^{1}$ Obstetrics and Gynecology Department, Assiut University, Assiut, Egypt

${ }^{2}$ Department of Dermatology, Venereology and Anderology, Assiut University, Assiut, Egypt

${ }^{3}$ Clinical Pathology Department, Assiut University, Assiut, Egypt

Please cite this paper as: Salman SA, Attallah DA, Ali MK, Hafez HA, Farghaly TA, Shaaban OM. Insulin sensitizing agent improves clinical pregnancy rate and insulin resistant parameters in polycystic ovarian syndrome patients with acanthosis nigricans: a randomized controlled study. Proc Obstet Gynecol. 2016;6(1): Article 2 [ 12 p.]. Available from: http://ir.uiowa.edu/pog/ Free full text article.

Corresponding author: Mohammed Khairy Ali, MD, Woman's Health Hospital, Assiut University, Assiut, Egypt. Business telephone number: +2088241621. Cellular phone number: +2 01005537951 Postal code: 71111. E-mail: m_khairy2001@yahoo.com

Financial Disclosure: The authors report no conflict of interest.

Received: 10 November 2015; accepted 28 January 2016; POG in Press, 28 January 2016

Copyright: (c) 2016 Salman et al. This is an open-access article distributed under the terms of the Creative Commons Attribution License, which permits unrestricted use, distribution, and reproduction in any medium, provided the original author and source are credited. 


\section{Introduction}

Polycystic ovary syndrome (PCOS) is the most common female endocrine disorder, with a prevalence ranging between $6 \%$ to $10 \%$ based on the National Institutes of Health (NIH) criteria. When the broader Rotterdam criteria are applied; the prevalence reaches as high as $15 \% .^{1}$ The typical presentation of POCS includes ovarian dysfunction (anovulation), hyperandrogenism (either clinical or biochemical), and the ultrasonographic picture of polycystic ovaries. ${ }^{2}$ The etiology of the syndrome is still unclear and the variability in clinical presentation continues to make the clinical and research implications challenging. ${ }^{3}$

Insulin resistance is a common finding in obese women with PCOS. ${ }^{4}$ The cellular and molecular mechanisms of insulin resistance in PCOS differ from other common insulin-resistant states such as obesity and type 2 diabetes mellitus (DM). ${ }^{5}$ PCOS and obesity both have a negative effect on insulin action. ${ }^{6}$ Pancreatic b-cell dysfunction is also present in PCOS but may be more related to type 2 DM risk factors such as women having first-degree relative with the DM. ${ }^{7}$

Acanthosis nigricans (AN) is a skin disease characterized by velvety, papillomatous, brownish-black and hyperkeratotic plaques. Typically it presents at intertriginous surfaces and the neck. AN is usually associated with obesity, insulin resistance and PSOS. ${ }^{8}$ Hyperkeratosis is increased in melanin pigmentation resulting in the dark color of $\mathrm{AN}^{9}{ }^{9}$ There is a subtle infiltrate composed of lymphocytes, plasma cells, and neutrophils as well as horn pseudocyst formation. Colloidal iron tissue staining often exhibits infiltration of the papillary dermis with glycosaminoglycans such as hyaluronic acid, especially in patients with PCOS. ${ }^{10}$

Elevated insulin concentrations result in direct and indirect activation of insulinlike growth factor 1 (IGF-1) receptors on keratinocytes and fibroblasts, leading to its proliferation. Other mediator's receptors may also contribute, including Epidermal Growth Factor Receptor (EGFR) and Fibroblast Growth Factor Receptor (FGFR). ${ }^{11}$ Hyperinsulinemia may also facilitate the development of AN indirectly by increasing the levels of free IGF-1 in the circulation. ${ }^{12}$ Insulinlike growth factor 1 binding protein and insulin-like growth factor 2 binding protein are decreased in obese women with hyperinsulinemia leading to an increase in plasma concentrations of free IGF-1. ${ }^{13}$

Metformin has a great effect on PCOS patients. This may be due to a reduction of pituitary secretion of $\mathrm{LH}$, a reduction of ovarian secretion of androgens, a reduction of adrenal secretion and finally an increased level of sex hormone binding globulin. ${ }^{14}$ Obesity is usually associated with hyperinsulinemia which is responsible for the low responsiveness of PCOS patients to clomiphene citrate. $^{15}$ A significant improvement in ovulation and pregnancy rates was reported when adding metformin to clomiphene citrate in clomiphene-resistant PCOS patients. ${ }^{16}$

The current study reviews the effect of adding metformin to clomiphene citrate in PCOS patients with acanthosis nigricans (AN) who were previously did 
Proceedings in Obstetrics and Gynecology, 2016;6(1): 2

not respond to $\mathrm{CC}$ alone. We hypothesized that adding metformin to this special group of women, AN patients with insulin resistance, may be beneficial for them including an improvement in pregnancy rate and hyperinsulinemia parameters.

\section{Materials and Methods}

The current study is a clinically registered double blinded, parallel, RCT (NCT02562664) compassing the effect of adding metformin to $\mathrm{CC}$ in PCOS patients who had acanthosis nigricans. The ethical review board of the Faculty of Medicine of the Assiut University approved the study. The participants were recruited from the Outpatient Infertility Clinic of the Woman's Health Hospital. It was carried out in the period between the first of August 2013 and the first of November 2014. This trial was designed and reported according to the revised recommendation of ClinicalTrials.gov for improving the quality of reporting RCTs.

\section{Eligible participants}

All participants who presented to the above clinic with acanthosis nigricans associated PCOS and previously not responding to $\mathrm{CC}$ were recruited in the study. The patient was considered eligible if she was under age 40 year, fulfilled at least 2 out of the three criteria of Rotterdam consensus 2003 and had AN. All participants had unsatisfactory ovulation after at least 3 months of CC induction. We excluded women with any contraindications to metformin such as liver disease, heart or respiratory failure, alcohol abuse, and kidney disease. All couples signed an informed consent to participate in the study.

\section{Randomization}

Randomization was done using a computer-generated random table. The participants who consented were randomly assigned to receive either CC with placebo or CC with metformin. Allocation concealment was done using serially numbered closed opaque envelopes. Each envelope was labeled with a serial number and had a card showing the intervention type inside. Allocation was never changed after opening the envelopes (study flow chart, Fig. 1).

\section{$\underline{\text { Intervention }}$}

All study participants had proper clinical evaluation to ensure the diagnosis of $A N$ (by assistant professor of dermatology D.A.A). Additionally, day 3 follicle stimulating hormone (FSH) level, fasting insulin, fasting glucose and homeostatic model assessment, to quantify insulin resistance (HOMA -IR), were done. Eligible participants were allocated to one of two groups. Group I received 100 mg clomiphene citrate (Clomid, global Napi , Egypt) from day 3 to day 7 of the cycle with placebo tablets which were taken twice daily continuously for three cycles. Group II received the above CC dose plus metformin (Cidophage, Amon , Egypt) 500 mg twice daily continuously for three cycles. Insulin resistance parameters as well as clinical pregnancy rate had been evaluated in both groups. The participants were requested to come to a monthly follow-up in our clinic for 3 months. Each participant had a special follow-up card that included the study serial number, the study group and the required follow-up schedule. 


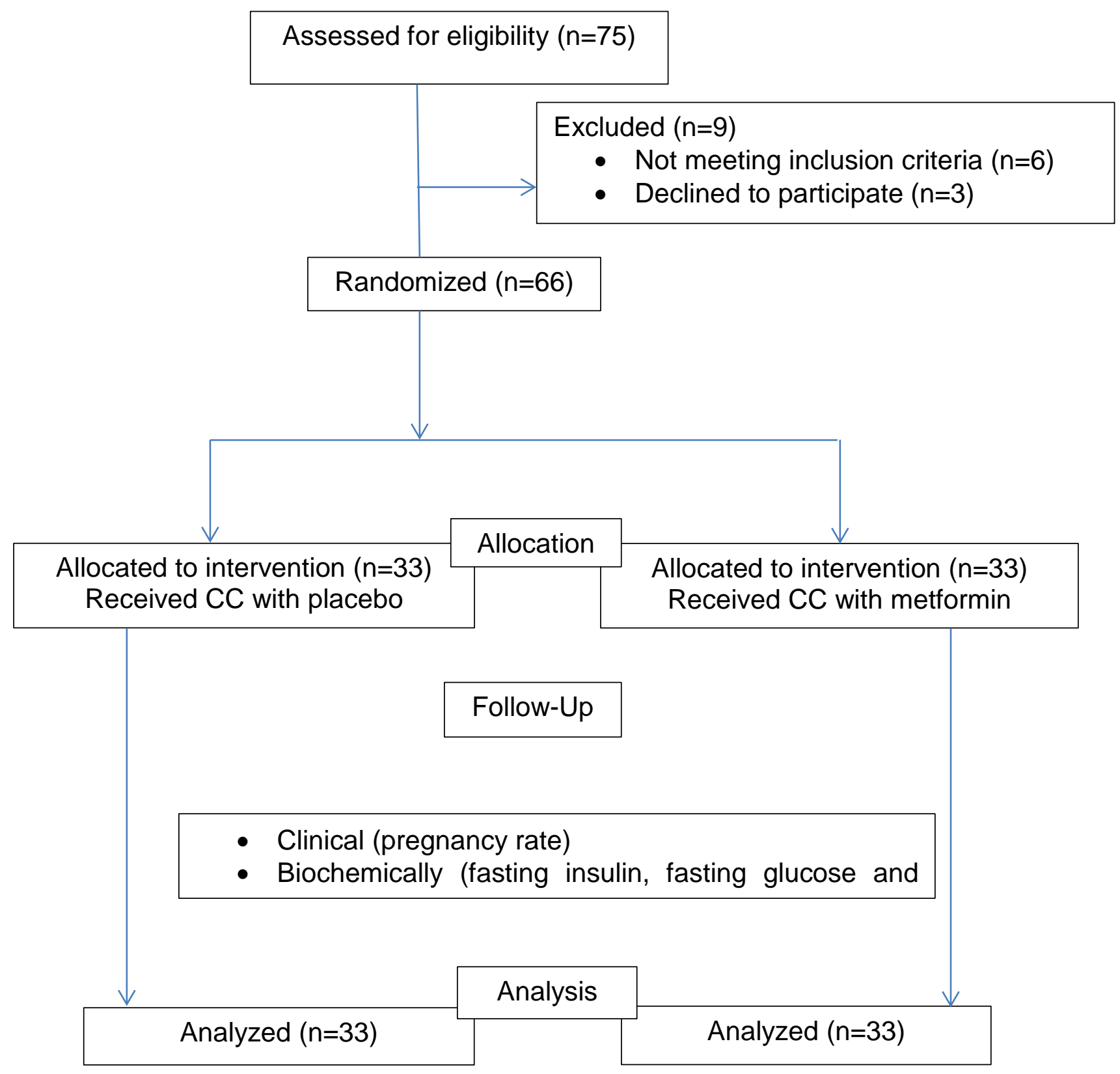

Figure 1: The study flow chart 


\section{Study outcomes}

The primary outcome of this study was the cumulative pregnancy rate after 3 months of treatment. Secondary outcomes included improvement of insulin resistance parameters such as fasting insulin, fasting glucose and homeostatic model assessment (HOMA $-I R)$.

\section{Follow-up schedule}

All study participants were followed at the end of the first, second and third months from the start of treatment. During each visit, we evaluated the patients clinically; we asked them to report their last menstrual period to ensure the pregnancy occurrence. When pregnancy occurred, 2D ultrasound was done to evaluate number of pregnancies. Finally, the insulin resistance parameters were assessed at the end of third month.

\section{Sample size}

The sample size calculation was based on the primary outcome (cumulative pregnancy rate). Previous randomized studies reported that the $\mathrm{CC}$ with metformin improved pregnancy rate from $8 \%$ to $24 \%$ after using CC with metformin. ${ }^{17}$ Using a two-sided chisquare $(x 2)$ test with an $\alpha$ of 0.05 , a total sample size was calculated to be at least 66 patients in the 2 groups (33 in each arm) with $80 \%$ power assuming a rate of loss to follow-up of 10\% (Epiinfo $^{\mathrm{TM}}$, Centers for Disease Control and Prevention, USA).

\section{Statistical analysis}

The data were collected and entered into a Microsoft Access database and were analyzed using the Statistical Package for Social Science (SPSS Inc., Chicago, version 16). The demographic characteristics and baseline data were compared between both groups. The outcome variables were calculated using a paired $t$ test to compare continuous variables before and after treatment and using an unpaired t test between groups. For dichotomous variables, chi-square was used to estimate the significance value. For analysis, $p>05$ was considered to be significant.

\section{Results}

Out of 75 recruited patients, 66 consented to participate. Of those nine women; three did not meet the inclusion criteria and six women were not willing to participate in an RCT. Basal characteristics of the study participants are given in Table 1 and showed that the two study groups were similar in mean age, duration of infertility, weight and height. Moreover; the studied women were also similar in the ovarian volume, antral follicle count (AFC), FSH, $\mathrm{LH}$ and prolactin (Table 1).

There were significant improvements in the insulin resistance parameters after three months of combining $\mathrm{CC}$ and metformin when compared with CC alone. After 3 months of treatment patients of group II had statistically significant improvement of fasting glucose $(P$ value $=0.001)$, fasting insulin $(p$ value $=0.005)$ and HOMA- IR $(P$ value $=0.001)($ Table 3 and 4$)$. 
Table 1: Patient demographic data

\begin{tabular}{|l|c|c|c|c|c|}
\hline \multirow{2}{*}{} & \multicolumn{2}{|c|}{$\begin{array}{c}\text { Group I } \\
\text { (CC+ placebo) } \\
\text { n=33 }\end{array}$} & \multicolumn{2}{c|}{$\begin{array}{c}\text { Group II } \\
\text { (CC+ } \\
\text { metformin) } \\
\text { n=33 }\end{array}$} & \multirow{2}{*}{ P. value } \\
\cline { 2 - 5 } & Mean & SD & Mean & SD & \\
\hline Age (years) & 26.12 & 5.24 & 24.91 & 3.34 & 0.05 \\
\hline Duration of infertility(years) & 5.00 & 3.10 & 3.94 & 1.70 & 0.05 \\
\hline Wt (Kg) & 78.03 & 8.11 & 78.58 & 8.18 & 0.787 \\
\hline Ovarian Volume(mL) & 11.97 & 2.37 & 11.32 & 1.87 & 0.220 \\
\hline Galactorrhea & 0.33 & 0.48 & 0.27 & 0.45 & 0.599 \\
\hline AFC & 13.15 & 1.72 & 13.39 & 2.03 & 0.602 \\
\hline FSH(MIU) & 5.50 & 1.34 & 5.44 & 1.73 & 0.866 \\
\hline LH(MIU) & 10.12 & 2.20 & 10.42 & 1.88 & 0.558 \\
\hline Prolactin(ng/mL) & 16.11 & 5.23 & 15.34 & 5.72 & 0.571 \\
\hline Endometrial thick(mm) & 8.69 & 2.04 & 9.04 & 2.27 & 0.515 \\
\hline Number of follicles at cycle 1 & 2.00 & 0.82 & 1.89 & 0.92 & 0.657 \\
\hline Number of follicles at cycle 2 & 1.77 & 0.76 & 2.04 & 0.94 & 0.261 \\
\hline Number of follicles at cycle 3 & 1.70 & 0.63 & 1.96 & 1.00 & 0.270 \\
\hline Progesterone day 21(ng/ml) & 14.79 & 6.33 & 14.95 & 4.67 & 0.932 \\
\hline
\end{tabular}

Wt weight, AFC antral follicle count, FSH follicular stimulating hormone, LH luteinized hormone

Table 2: Cumulative pregnancy rate after 3 months of treatment

\begin{tabular}{|c|c|c|c|c|c|}
\hline & \multicolumn{2}{|c|}{$\begin{array}{c}\text { Group I } \\
(\mathrm{CC}+\text { placebo }) \\
\mathbf{n}=33\end{array}$} & \multicolumn{2}{|c|}{$\begin{array}{c}\text { Group II } \\
\text { (CC+ metformin) } \\
n=33\end{array}$} & \multirow[t]{2}{*}{ P. value } \\
\hline & No. & $\%$ & No. & $\%$ & \\
\hline PR from cycle 1 & 2 & 6.1 & 3 & 9.1 & NS \\
\hline Singleton & 2 & 6.1 & 0 & 0.0 & NS \\
\hline Twin & 0 & 0.0 & 3 & 9.1 & NS \\
\hline Abortion & 0 & $0 \%$ & 1 & $3 \%$ & NS \\
\hline PR from cycle 2 & 5 & 15.2 & 12 & 36.4 & NS \\
\hline Singleton & 4 & 12.2 & 10 & 30.3 & NS \\
\hline Twin & 1 & 3.0 & 2 & 6.1 & NS \\
\hline Abortion & 0 & $0 \%$ & 1 & $3 \%$ & NS \\
\hline \multicolumn{6}{|l|}{ PR from cycle 3} \\
\hline Abortion & 0 & $0 \%$ & 1 & $3 \%$ & NS \\
\hline Three cycles PR & 7 & 21.2 & 18 & 54.5 & 0.033* \\
\hline
\end{tabular}

*Statistically significant difference $(p<.05)$. PR pregnancy rate

Metformin \& clomiphene citrate in PCOS with acanthosis nigricans 
Table 3: Insulin parameters before treatment

\begin{tabular}{|l|l|r|l|l|l|}
\hline \multirow{2}{*}{} & \multicolumn{1}{|c|}{$\begin{array}{c}\text { Group I } \\
\text { (CC+ placebo) } \\
\mathbf{n = 3 3}\end{array}$} & $\begin{array}{c}\text { Group II } \\
\text { (CC+ metformin) } \\
\text { n=33 }\end{array}$ & \multirow{2}{*}{ P. value } \\
\cline { 2 - 5 } & Mean & SD & Mean & SD & \\
\hline Fasting glucose( mg/dL) & 102.12 & 8.85 & 99.70 & 9.23 & 0.280 \\
\hline Fasting insulin (mg/dL) & 11.57 & 2.73 & 12.60 & 3.91 & 0.364 \\
\hline HOMA_IR (mg/dL) & 2.88 & 0.63 & 3.07 & 0.87 & 0.467 \\
\hline Progesterone D 21(ng/ml) & 14.79 & 6.33 & 14.95 & 4.67 & 0.932 \\
\hline
\end{tabular}

HOMA_IR homeostatic model assessment of insulin resistance

Table 4: Insulin parameters after 3 months treatment

\begin{tabular}{|lccccc|} 
& $\begin{array}{c}\text { Group I } \\
\text { (CC+ placebo) } \\
\text { n=33 }\end{array}$ & \multicolumn{3}{c|}{$\begin{array}{c}\text { Group II } \\
\text { (CC+ metformin) } \\
\text { n=33 }\end{array}$} & P. value \\
& Mean & SD & Mean & SD & \\
\hline Fasting glucose( mg/dL) & 96.85 & 6.84 & 89.76 & 6.22 & $0.001^{*}$ \\
\hline Fasting insulin( $\mathbf{m g} / \mathbf{d L})$ & 12.06 & 3.12 & 7.83 & 2.95 & $0.005^{*}$ \\
\hline HOMA_IR( mg/dL) & 2.90 & 0.71 & 1.72 & 0.67 & $0.001^{*}$ \\
\hline
\end{tabular}

*Statistically significant difference $(p<.05)$. HOMA_IR homeostatic model assessment of insulin resistance

\section{Discussion}

Our data showed that adding metformin to clomiphene citrate for three cycles of ovulation induction in PCOS patients resistant to clomiphene citrate with acanthosis nigricans not only improved the cumulative pregnancy rate but also the insulin resistance parameters e.g. fasting insulin, fasting glucose and HOMA-IR.

Acanthosis nigricans is one of the clinical parameters indicating insulin resistance especially in patients with PCOS. ${ }^{9}$ Hence, the basis for the hypothesis that AN patients would benefit from the addition of metformin to clomiphene citrate by increasing glucose hepatic utilization accompanied by an improved metabolic profile, a significant reduction in hyperandrogenemia, and an improvement in ovulation and menstruation pattern. ${ }^{18}$

In developing countries where it is financially prohibitive to perform the insulin parameters for all clomiphene citrate resistant patients, AN can be used as clinical sign indicating insulin resistance and thus recommending the addition of metformin to clomiphene citrate in their treatment protocol.

The same data were published by 
Neveu et al. who proved that metformin is better for ovulation induction than CC alone and they suggested using of metformin as a first line for ovulation induction in patients with PCOS regardless of their weight and insulin levels. However; they found no significant difference in the pregnancy achievement which differs from our study as we found more cumulative pregnancy rate with using $\mathrm{CC}$ with metformin. ${ }^{19}$ Our results were in agreement with data published by Khorram et al. who concluded that adding metformin with $\mathrm{CC}$ reduced serum insulin, insulin resistance and increased SHBG levels, resulting in an improved response to $\mathrm{CC}^{20}$

Ben Ayed and colleagues support our results because they found a significant improvement of the ovulatory response to clomiphene citrate in PCOS women when adding metformin. ${ }^{21}$ The same results were also observed by Dasari et al. who reported that the ovulatory rate and the pregnancy rate with the metformin-CC combination was higher when compared with CC alone. ${ }^{17}$

The conclusion of the systematic review conducted by Siebert et al. is that CC alone is superior to metformin alone regarding live birth rate and ovulation. The combination (CC+ metformin) is superior to CC alone as a primary method for ovulation induction and to achieve pregnancy in PCOS. ${ }^{22}$ Kar et al. reported similar results and proved that metformin is as good as CC in terms of live birth rate and the combination of $\mathrm{CC}$ and metformin gave the highest ovulation and live birth rate. ${ }^{23}$ The last published study was by Shigiyama et al. in 2016 who successfully treated a lean PCOS patient with type 1 diabetes by metformin. However; they concluded that the hyperinsulinemia associated with type 1 diabetes potentially exacerbates PCOS through hyperandrogenism. Therefore, metformin is recommended for lean PCOS with type 1 diabetes as well as for common obese PCOS with type 2 diabetes. $^{24}$

Rosiglitazone is another insulin sensitizer that acts through increased production of insulin-sensitive adipocytes and increased glucose uptake. Many published studies suggest using it in PCOS due to its beneficial effect on hyperandrogenism, insulin resistant and anovulation in both lean and obese women with PCOS. ${ }^{25}$ Yilmaz et al. found that both metformin and rosiglitazone increased insulin sensitivity in obese and lean patients with PCOS and they also found that rosiglitazone seemed to be more effective in decreasing the androgen levels and in achieving a slightly higher improvement in menstrual disturbance than metformin. ${ }^{26}$ Dereli et al. demonstrated in their study that rosiglitazone improved the ovulatory dysfunction, hirsutism, hyperandrogenemia, and insulin resistance of PCOS with minimal adverse effects. In addition; this drug may be a good choice for patients with PCOS, especially for the ones who failed to show satisfactory results in metformin therapy. ${ }^{27}$

It was noticed that the gastrointestinal side effects of metformin were dramatically improved when the patients used them during meals as recommended by previous studies. ${ }^{28}$ This improvement enabled us to continue using metformin with $\mathrm{CC}$ for three successive months. 
In our study we selected patients with acanthosis nigricans assuming that those patients would have more response to the addition of metformin to CC for three cycles of stimulation. Limitations of our study include small sample size and not evaluating the effect of metformin on improving AN from the dermatological perspective. Still more data is needed to support the effect of insulin sensitizers on improving the pregnancy rate in the $\mathrm{CC}$ resistance PCOS patients who have acanthosis nigricans.

\section{Conclusion}

The addition of metformin to $\mathrm{CC}$ in clomiphene citrate resistant PCOS patients who have acanthosis nigricans improves both pregnancy rate and hyperinsulinemia parameters.

\section{References}

1. Fauser $B C$, Tarlatzis $B C$, Rebar RW, Legro RS, Balen AH, Lobo R, Carmina E, Chang J, Yildiz BO, Laven JS, Boivin $\mathrm{J}$, Petraglia F, Wijeyeratne CN, Norman RJ, Dunaif A, Franks S, Wild RA, Dumesic D, Barnhart K. Consensus on women's health aspects of polycystic ovary syndrome (PCOS): the Amsterdam ESHRE/ASRM-Sponsored 3rd PCOS Consensus Workshop Group. Fertil Steril. 2012 Jan;97(1):28-38.e25. http://dx.doi.org/10.1016/j.fertnstert.201 1.09.024 Epub 2011 Dec 6. PubMed PMID: 22153789.

2. SalaheldinAbdelHamidAM, Rateb AM, Ismail Madkour WA. Is clomiphene citrate stair-step protocol a good alternative to gonadotrophins in clomiphene-resistant PCO patients? Prospective study. J Obstet Gynaecol Res. 2016 Jan 19. http://dx.doi.org/10.1111/jog.12940 [Epub ahead of print] PubMed PMID: 26786750.
3. Ansari RM. Potential use of durian fruit (Duriozibenthinus Linn) as an adjunct to treat infertility in polycystic ovarian syndrome. J Integr Med. 2016Jan;14(1):22-8. http://dx.doi.org/10.1016/S20954964(16)60240-6 PubMed PMID: 26778225.

4. Ganie MA, Marwaha RK, Nisar S, Farooqi KJ, Jan RA, Wani SA, Gojwari $T$, Shah ZA. Impact of hypovitaminosis $D$ on clinical, hormonal and insulin sensitivity parameters in normal body mass index polycystic ovary syndrome women. J Obstet Gynaecol. 2016 Jan 15:1-5. [Epub ahead of print] http://dx.doi.org/10.3109/01443615.201 5.1103715 PubMed PMID: 26772667.

5. Tang $\mathrm{W}$, Wang $\mathrm{Y}$, Jiang $\mathrm{H}$, Liu $\mathrm{C}$, Dong C, Chen S, Kang M, Gu H. Insulin receptor substrate-1 (IRS-1) rs1801278G $>$ A polymorphism is associated with polycystic ovary syndrome susceptibility: a metaanalysis. Int J Clin Exp Med. 2015 Oct 15;8(10):17451-60. eCollection 2015. PubMed PMID: 26770335.

6. Greenwood EA, Pasch LA, Shinkai K, Cedars MI, Huddleston HG. Putative role for insulin resistance in depression risk in polycystic ovary syndrome. Fertil Steril. 2015 Sep;104(3):707-14.e1. http://dx.doi.org/10.1016/i.fertnstert.201 5.05.019 Epub2015 Jun 19. PubMed PMID: 26054555.

7. Chen L, Xu WM, Zhang D. Association of abdominal obesity, insulin resistance, and oxidative stress in adipose tissue in women with polycystic ovary syndrome. Fertil Steril. 2014 Oct; 102(4):11671174.e4. http://dx.doi.org/10.1016/j.fertnstert.201 4.06.027 Epub 2014 Jul 23. Erratum in: Fertil Steril. 2014 Nov;102(5):1499. PubMed PMID: 25064406. 
8. Schmidt $\mathrm{TH}$, Khanijow K, Cedars MI, Huddleston $\mathrm{H}$, Pasch L, Wang ET, Lee J, Zane LT, Shinkai K. Cutaneous findings and systemic associations in women with polycystic ovary syndrome. JAMA Dermatol. 2015 Dec 23:1-8. http://dx.doi.org/10.1001/jamadermatol.2 015.4498 [Epub ahead of print] PubMed PMID: 26720591.

9. Gowri BV, Chandravathi PL, Sindhu PS, Naidu KS. Correlation of skin changes with hormonal changes in polycystic ovarian syndrome: a cross-sectional study clinical study. Indian J Dermatol. 2015 Jul-Aug;60(4):419. http://dx.doi.org/10.4103/00195154.160505 PubMed PMID: 26288423.

10. Islam S, Pathan F, Ahmed T. Clinical and biochemical characteristics of polycystic ovarian syndrome among women in Bangladesh. Mymensingh Med J. 2015 Apr;24(2):310-8. PubMed PMID: 26007259.

11. Baer TE, Milliren CE, Walls C, DiVasta AD. Clinical variability in cardiovascular disease risk factor screening and management in adolescent and young adult women with polycystic ovary syndrome. J PediatrAdolesc Gynecol. $2015 \quad$ Oct;28(5):317-23. http://dx.doi.org/10.1016/j.jpag.2014.09. 010 Epub 2014 Oct 8. PubMed PMID: 26081478.

12. Desai NA, Patel SS. Increased insulinlike growth factor-1 in relation to cardiovascular function in polycystic ovary syndrome: friend or foe? GynecolEndocrinol. 2015 Oct;31(10):801-7. http://dx.doi.org/10.3109/09513590.201 5.1075497 Epub2015 Aug 18. PubMed PMID: 26288196.
13. Çakir E, Topaloğlu O, Çolak Bozkurt N, Karbek Bayraktar B, Güngüneş A, Sayki Arslan M, Özturk Ünsal İ, Tutal E, Ucan $B$, Delibasi T. Insulin-like growth factor 1, liver enzymes, and insulin resistance in patients with PCOS and hirsutism. Turk J Med Sci. 2014;44(5):781-6. doi:10.3906/sag-1303-80

14. Stepto NK, Cassar S, Joham AE, Hutchison SK, Harrison CL, Goldstein $\mathrm{RF}$, Teede HJ. Women with polycystic ovary syndrome have intrinsic insulin resistance on euglycaemichyperinsulaemic clamp. Hum Reprod. 2013 Mar;28(3):777-84. http://dx.doi.org/10.1093/humrep/des46 $\underline{3}$ Epub 2013 Jan 12. PubMed PMID: 23315061.

15. Shao R, Li X, Billig $\mathrm{H}$. Promising clinical practices of metformin in women with PCOS and early-stage endometrial cancer. BBA Clin. 2014 Jul 25;2:7-9. eCollection 2014 Dec. http://dx.doi.org/10.1016/j.bbacli.2014.0 7.001 PubMed PMID: 26674650

16. Mhao NS, Al-Hilli AS, Hadi NR, Jamil DA, Al-Aubaidy HA. A comparative study to illustrate the benefits of using ethinyl estradiol-cyproterone acetate over metformin in patients with polycystic ovarian syndrome. Diabetes MetabSyndr. 2015 Nov 12. pii: S18714021(15)30051-5.

http://dx.doi.org/10.1016/i.dsx.2015.10.0 01 [Epub ahead of print] PubMed PMID: 26703220.

17. Dasari P, Pranahita GK. The efficacy of metformin and clomiphene citrate combination compared with clomiphene citrate alone for ovulation induction in infertile patients with PCOS. J Hum Reprod Sci. 2009 Jan-Jun; 2(1): 18-22. http://dx.doi.org/10.4103/0974$\underline{1208.51337}$ 
18. Tang T, Lord JM, Norman RJ, Yasmin $\mathrm{E}$, Balen $\mathrm{AH}$. Insulin-sensitising drugs (metformin, rosiglitazone, pioglitazone, D-chiro-inositol) for women with polycystic ovary syndrome, oligo amenorrhoea and subfertility. Cochrane Database Syst Rev. 2010 Jan 20;(1):CD003053.

http://dx.doi.org/10.1002/14651858.CD0 03053.pub4 Update in: Cochrane Database Syst Rev. 2012;5:CD003053. PubMed PMID: 20091537.

19. Neveu N, Granger L, St-Michel P, Lavoie HB. Comparison of clomiphene citrate, metformin, or the combination of both for first-line ovulation induction and achievement of pregnancy in 154 women with polycystic ovary syndrome. Fertil Steril. 2007 Jan;87(1):113-20. Epub $2006 \quad$ Nov 1. http://dx.doi.org/10.1016/j.fertnstert.200 6.05.069 PubMed PMID: 17081535.

20. Khorram O, Helliwell JP, Katz S, Bonpane CM, Jaramillo L. Two weeks of metformin improves clomiphene citrateinduced ovulation and metabolic profiles in women with polycystic ovary syndrome. Fertil Steril. 2006 May;85(5):1448-51. Epub 2006 Mar 31. http://dx.doi.org/10.1016/i.fertnstert.200 5.10.042 PubMed PMID: 16579997.

21. Ben Ayed B, Dammakdit Mlik S, Ben Arab $\mathrm{H}$, Trabelssi $\mathrm{H}$, Chahtour $\mathrm{H}$, Mathlouthi $N$, Dhuib $M$, Kassis $M$, Saiidane D, Trabelssi K, Guermazi M. Metformin effects on clomifene-induced ovulation in the polycystic ovary syndrome. Tunis Med. 2009 Jan;87(1):43-9. PubMed PMID: 19522426.

22. Siebert TI, Viola MI, Steyn DW, Kruger TF. Is metformin indicated as primary ovulation induction agent in women with PCOS? A systematic review and metaanalysis. Gynecol Obstet Invest. 2012;73(4):304-13.

http://dx.doi.org/10.1159/00033525

Epub 2012 Apr 17. PubMed PMID: 22516925.
23. Kar S, Sanchita S. Clomiphene citrate, metformin or a combination of both as the first line ovulation induction drug for Asian Indian women with polycystic ovarian syndrome: A randomized controlled trial. J Hum Reprod Sci. 2015 Oct-Dec;8(4):197-201. doi:10.4103/0974-1208.170373. PubMed PMID: 26752854.

24. Shigiyama $F$, Kumashiro $N$, Rikitake $T$, Usui S, Saegusa M, Kitamura M, Uchino $\mathrm{H}$, Hirose T. A case of lean polycystic ovary syndrome with early stage of type 1 diabetes successfully treated with metformin [Rapid Communication]. Endocr J. 2016 Jan 13. [Epub ahead of print]

http://doi.org/10.1507/endocri.EJ150548 PubMed PMID: 26765270.

25. Baillargeon JP, Jakubowicz DJ, luorno $\mathrm{MJ}$, Jakubowicz S, Nestler JE. Effects of metformin and rosiglitazone, alone and in combination, in nonobese women with polycystic ovary syndrome and normal indices of insulin sensitivity. Fertil Steril. 2004 Oct;82(4):893-902. http://dx.doi.org/10.1016/i.fertnstert.200 4.02.127 PubMed PMID: 15482765.

26. Yilmaz $M$, Biri $A$, Karakoç $A$, Törüner $F$, Bingöl B, Cakir N, Tiras B, Ayvaz G, Arslan $M$. The effects of rosiglitazone and metformin on insulin resistance and serum androgen levels in obese and lean patients with polycystic ovary syndrome. J Endocrinol Invest. 2005 Dec;28(11):1003-8. http://dx.doi.org/10.1007/BF03345339 PubMed PMID: 16483179.

27. Dereli D, Dereli T, Bayraktar F, Ozgen AG, Yilmaz C. Endocrine and metabolic effects of rosiglitazone in non-obese women with polycystic ovary disease. EndocrJ. 2005 Jun;52(3):299-308. http://dx.doi.org/10.1507/endocri.52.299 PubMed PMID: 16006724. 
Proceedings in Obstetrics and Gynecology, 2016;6(1): 2

28. Stepensky D, Friedman M, Srour W, Raz I, Hoffman A. Preclinical evaluation of pharmacokinetic-pharmacodynamic rationale for oral $\mathrm{CR}$ metformin formulation. J Control Release. 2001
Mar 12;71(1):107-15.

http://dx.doi.org/10.1016/S01683659(00)00374-6 PubMed PMID: 11245912. 